\title{
The impact of different maximum speeds on journey times, energy use, headway times and the number of trains required for Phase One of Britain's High Speed Two line
}

\author{
D. Hasegawa, G. L. Nicholson, C. Roberts \& F. Schmid \\ Birmingham Centre for Railway Research and Education, \\ University of Birmingham, $U K$
}

\begin{abstract}
The maximum speed of High Speed Rail (HSR) operations has increased over the past few years. Indeed, it is planned to operate the new High Speed Two (HS2) line in Britain at $330 \mathrm{~km} / \mathrm{h}$, once the first phase is completed in 2026 . This will lead to very short journey times from London to Birmingham. However, as a direct result of the higher speeds, the energy used by HSR trains has increased, despite the significant technical advances in train construction over the past 50 years. In spite of a broad understanding of this issue, there has been no formal assessment as to the overall benefit of operating HSR trains at very high speeds. Also, as is the case for HS2, the construction of HSR lines is usually split into multiple phases, to reduce both the project management and financial risks. At partial opening, the length of the route is shorter than at full opening, so the ideal maximum speed could well be different. To date, there has been no specific study about the most effective operation during this period. Choosing a lower maximum speed of operation is a possible option for reducing energy use but this lengthens journey times, thus risking a reduction in the market share of HSR and an increase in the number of trains required. Conversely, increasing the line speed not only increases energy consumption but also the headway time of the line. In this paper, various maximum operating speeds for Phase One of HS2 are analysed by simulation, in terms of journey time, energy consumption, headway time and the number of trains required. Advantages and drawbacks of adopting a lower maximum speed are presented.
\end{abstract}

Keywords: High Speed Rail, energy, headway, capacity, partial opening. 


\section{Introduction}

The first dedicated High Speed Railway (HSR), the Japanese Shinkansen, began operation in 1964 with a maximum operational speed of $210 \mathrm{~km} / \mathrm{h}$. Other HSR lines have since been constructed in Europe and Asia, with ever increasing maximum speeds of operation (Figure 1). Today, many HSR trains run at over $300 \mathrm{~km} / \mathrm{h}$ and, for example, the new HSR project in Britain, High Speed Two (HS2), is planned to be operated at $330 \mathrm{~km} / \mathrm{h}$ (maximum line speed is $360 \mathrm{~km} / \mathrm{h}$ ) in 2026 from London to Birmingham during Phase One and into the future [1]. Any increase in the maximum speed of operation shortens the journey time, however, it also increases energy consumption. Due to concerns about economic and environmental problems, the relationship between high speed and energy consumption has been studied extensively [2-8]. These studies though tend to concentrate on journey time and energy use. However, to provide practical results, railway operations should be evaluated based on timetabled multi-train operation, meaning that headway time, the scheduling of rolling stock and the rostering of staff must also be considered. An increase of the operational speed above an optimal level increases the headway time and thus could cause a decrease in capacity [9]. By contrast, a decrease in the operating speed increases the number of trains required to operate a given service [10]. These issues have not been considered in the published literature.

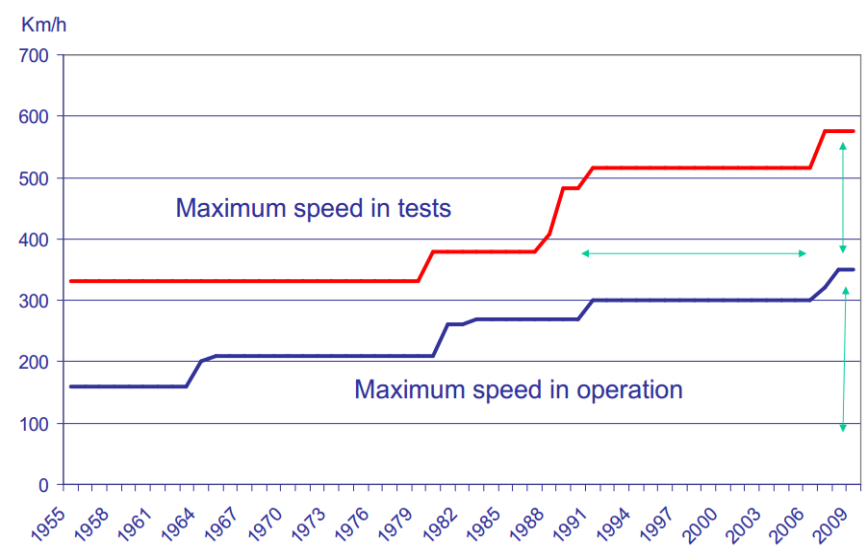

Figure 1: $\quad$ Increase in maximum speeds in the operation of HSRs [11].

Also, as is the case for HS2, construction of HSR lines generally has multiple phases, in order to reduce the financial and operational risks. However, to date no operational study about the best approaches to partial opening of High Speed Lines (HSLs) has been conducted. In this paper, service options with different operational speeds for the partial opening of the new British HSL project, HS2 Phase One, are simulated and analysed in terms of journey time, energy consumption, headway time, and the number of trains required. 


\section{Theoretical background}

For the analysis of operational options with various maximum speeds, the theoretical background to the simulation of journey time, energy consumption, headway time, and the number of trains required is presented in this section.

\subsection{Journey time and energy consumption calculation}

A single train simulator (STS) was used for calculating the tractive force (tractive effort), resistance, velocity, journey time and energy consumption [12]. The design of the STS is based on the theory presented below. The force related to train motion is given as a form of Newton's second law of motion:

$$
F_{t}-F_{r}-F_{g}-F_{c}=M_{e} a,
$$

with $\mathrm{F}_{\mathrm{t}}$ : tractive force, $\mathrm{F}_{\mathrm{r}}$ : running resistance force, $\mathrm{F}_{\mathrm{g}}$ : resistance force from gradient, $\mathrm{F}_{\mathrm{c}}$ : resistance force from curvature $[\mathrm{N}], \mathrm{M}_{\mathrm{e}}$ : effective mass $[\mathrm{kg}]$, a: acceleration $\left[\mathrm{m} / \mathrm{s}^{2}\right]$. The effective mass is given by

$$
M_{e}=M_{t}(1+\lambda)+M_{p}
$$

where $M_{t}$ is tare mass, $\lambda$ is the rotary allowance (typically 0.05 to 0.15 ), and $M_{p}$ is the payload. Running resistance is given by

$$
F_{r}=A+\mathrm{B} v+C v^{2} .
$$

This equation is the Davis equation [13]. A is a coefficient related to the rolling resistance, $\mathrm{B}$ is related to bearing friction coefficient, $\mathrm{C}$ is related to the aerodynamic drag coefficient, and $v$ is velocity $[\mathrm{m} / \mathrm{s}]$. At high speeds, the contribution of the aerodynamic drag becomes dominant. Resistance from a gradient is given by

$$
F_{g}=\left(M_{t}+M_{p}\right) g \sin \alpha \approx\left(M_{t}+M_{p}\right) g * n / 1000
$$

The acceleration due to gravity is $\mathrm{g}$, and $\alpha$ is the gradient of the line. In reality, $\alpha$ is such a small angle that $\sin \alpha$ can be approximated by $\tan \alpha$, which is generally measured as $\mathrm{n}[\mathrm{m}]$ of rise or fall in one thousand metres, that is, \%. Resistance from curvature is given by

$$
F_{c}=\left(M_{t}+M_{p}\right) g * 1 / 1000 * 700 / R,
$$

where $\mathrm{R}$ is the radius of the curve. This equation means that the resistance force of curvature with a radius of $700 \mathrm{~m}$ has the same magnitude as the gradient force of a $1 \%$ gradient $[14,15]$. In the case of HSR, $\mathrm{R}$ is generally large enough to ignore the effect of $\mathrm{F}_{\mathrm{c}}$. The power of the traction system $\left(\mathrm{P}_{\mathrm{t}}\right)[\mathrm{W}]$, tractive force $\left(\mathrm{F}_{\mathrm{t}}\right)$ and velocity $(v)$ have the following relationship: 


$$
P_{t}=F_{t} v
$$

Energy consumption at the wheel $\left(\mathrm{EC}_{\text {wheel }}\right)$ is calculated by the integration of $\mathrm{F}_{\mathrm{t}}$ with respect to distance $(x)$. Journey time $(\mathrm{T})$ is also calculated by the integration of time $(t)$ for each calculation step,

$$
\begin{gathered}
E C_{\text {wheel }}=\int F_{t} d x=\int \frac{P_{t}}{v} d x . \\
\mathrm{T}=\int t d x=\int \frac{\mathrm{x}}{v} d x
\end{gathered}
$$

As a first approximation, the energy consumption by auxiliary power needs $\left(\mathrm{P}_{\mathrm{a}}\right)$ is a function of journey time $(\mathrm{T})$ although it also depends on the comfort level required and the outside temperature:

$$
E C_{\text {auxiliary }}=P_{a} T
$$

Energy consumption of a single train, EC, is given in terms of the efficiency of the traction system, $\eta, 0 \leq \eta \leq 1$,

$$
E C=\eta E C_{\text {wheel }}+E C_{\text {auxiliary }}
$$

In this study, equation (8) is used to calculate journey time and equation (10) is used in the energy consumption calculation.

\subsection{Headway time calculation}

Headway time is "the minimum time between trains that the signalling will permit, so that the train ahead does not affect a following train" [9]. Headway time is important for both safety and capacity (maximum number of trains per hour for a direction). For the calculation of the capacity of HS2, headway time has been presented in several reports [16-18]. The theoretical headway time [s] for plain line with homogenous operation, based on the use of Level 2 of the European Train Control System with short train detection sections, is given by

$$
\text { Headway time }=\frac{\left(L_{s}+L_{t}+L_{b}+B D\right)}{v}+\mathrm{C},
$$

where $\mathrm{L}_{\mathrm{s}}, \mathrm{L}_{\mathrm{t}}, \mathrm{L}_{\mathrm{b}}$ are the lengths $[\mathrm{m}]$ of, respectively, the train detection section, the train and a buffer distance for safety. BD [m] is the braking distance of the following train. $\mathrm{C}$ is a constant time which derives from the signalling system behaviour and is of the order of a few seconds. $v$ is the speed of the train $[\mathrm{m} / \mathrm{s}]$ and $\mathrm{BD}$ is given by

$$
\mathrm{BD}=\frac{v^{2}}{2 d e c},
$$

where $d e c$ is the braking rate $\left[\mathrm{m} / \mathrm{s}^{2}\right]$. A smaller headway allows more services and more flexible timetabling. 


\subsection{Number of trains required}

Calculation of the precise number of trains required $\left(\mathrm{N}_{\mathrm{r}}\right)$ requires a roster of the trains. However, during the planning phase, for a cyclic timetable, it can be regarded simply as a function of journey time (T), turnaround time at the terminal $\left(\mathrm{T}_{\mathrm{a}}\right)$, and the time interval of two successive departures $\left(\mathrm{T}_{\mathrm{i}}\right)$.

$$
N_{r}=\text { ceiling }\left[2\left(T+T_{a}\right) / T_{i}\right] .
$$

Say, $T[\mathrm{~min}]$ is the same for services in both directions, $T_{a}[\mathrm{~min}]$ is also the same for both terminals, and $T_{i}[\mathrm{~min}]$ is constant for every successive departure. The numerator of the right hand side of (13) is the time required for one train to depart from a terminal station, finish its round trip and depart the origin station again. If the time is less than or equal to the train's departure time plus $T_{i}$ (the next scheduled departure time), the required train sets for a direction is only one [10]. To decrease the number of required train sets requires a decrease of the sum of $\mathrm{T}$ and $\mathrm{T}_{\mathrm{a}}$ or an increase of $\mathrm{T}_{\mathrm{i}}$.

\section{Simulation results and discussion}

For HS2 Phase One, the planned maximum operating speed is $330 \mathrm{~km} / \mathrm{h}$ in order to obtain a margin, while the maximum line speed is $360 \mathrm{~km} / \mathrm{h}$. In this section, the route (post public consultation) from London Euston to Birmingham Curzon Street has been simulated for maximum speeds of between $200 \mathrm{~km} / \mathrm{h}$ and $360 \mathrm{~km} / \mathrm{h}$ (step: $10 \mathrm{~km} / \mathrm{h}$ ) for two coupled $200 \mathrm{~m}$ long Automotrices Grande Vitesse 11 (AGV-11). The journey time and energy consumption of a single train, headway time for plain line, and the number of rolling stock required for each maximum speed are presented. In addition to these results, operational options with lower maximum speeds are discussed.

\subsection{Journey time and energy consumption}

The parameters required by the STS were defined as shown in Table 1. The calculated journey times and energy consumption values are shown in Figure 2. The journey at $330 \mathrm{~km} / \mathrm{h}$ takes about 49 minutes, which is the same as given in the project specification of HS2 [19]. Journey time decreases and energy consumption increases as the maximum speed increases. The latter is expected to increase in proportion to the square of the speed; however, this profile appears to be linear because the train can only run part of the route at maximum speed (see Figure 3). Thus, changing the maximum speed only affects a very small portion of the journey.

The speed-distance graph in Figure 3, showing the route from London Euston to Birmingham Curzon Street, includes two intermediate stops, namely, Old Oak Common and Birmingham Interchange. 
Table 1: $\quad$ Required parameters for the STS of HS2 Phase One from London to Birmingham.

\begin{tabular}{|c|c|c|c|}
\hline \multicolumn{2}{|l|}{ Parameters } & \multirow{2}{*}{\begin{tabular}{|l} 
Value \\
$175.230 \mathrm{~km}$
\end{tabular}} & \multirow{2}{*}{$\frac{\text { Sources }}{[20]}$} \\
\hline \multirow{3}{*}{ Line } & Distance & & \\
\hline & Gradient & Route after consultation & {$[21]$} \\
\hline & Speed limit & Route after consultation & {$[20,21]$} \\
\hline \multirow{8}{*}{ Vehicle } & Mass & $820 \mathrm{t}($ tare $)+82.5 \mathrm{t}$ (passenger) & {$[20]$} \\
\hline & Davis equation parameters & $\begin{array}{l}\mathrm{A}=14.4 \mathrm{kN}, \mathrm{B}=0.084 \mathrm{kNs} / \mathrm{m} \\
\mathrm{C}=0.013 \mathrm{kNs}^{2} / \mathrm{m}^{2}\end{array}$ & {$[5]$} \\
\hline & Maximum tractive force & $546 \mathrm{kN}$ & {$[22]$} \\
\hline & Power & $16.8 \mathrm{MW}$ & {$[22]$} \\
\hline & Auxiliary power needs & $1170 \mathrm{~kW}$ & {$[5]$} \\
\hline & Regenerative braking & $80 \%$ efficiency & {$[3]$} \\
\hline & Traction system efficiency & 0.823 & {$[3]$} \\
\hline & Number of seats & 1100 & {$[20]$} \\
\hline \multirow{4}{*}{ Operation } & Maximum speed & $200-360 \mathrm{~km} / \mathrm{h}$ & Author \\
\hline & Stops & 2 stops, dwell time is $2 \mathrm{~min}$ & {$[20]$} \\
\hline & Braking rate & $0.78 \mathrm{~m} / \mathrm{s}^{2}$ & {$[20]$} \\
\hline & Driving style & Flat out & {$[20]$} \\
\hline
\end{tabular}

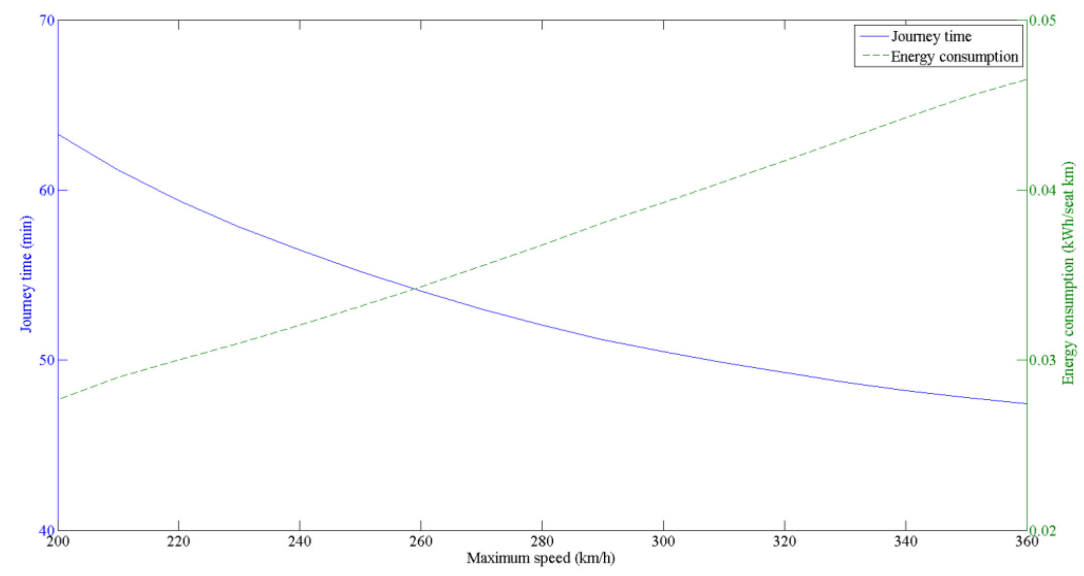

Figure 2: Journey time and energy consumption of HS2 Phase One from London Euston to Birmingham Curzon Street. 


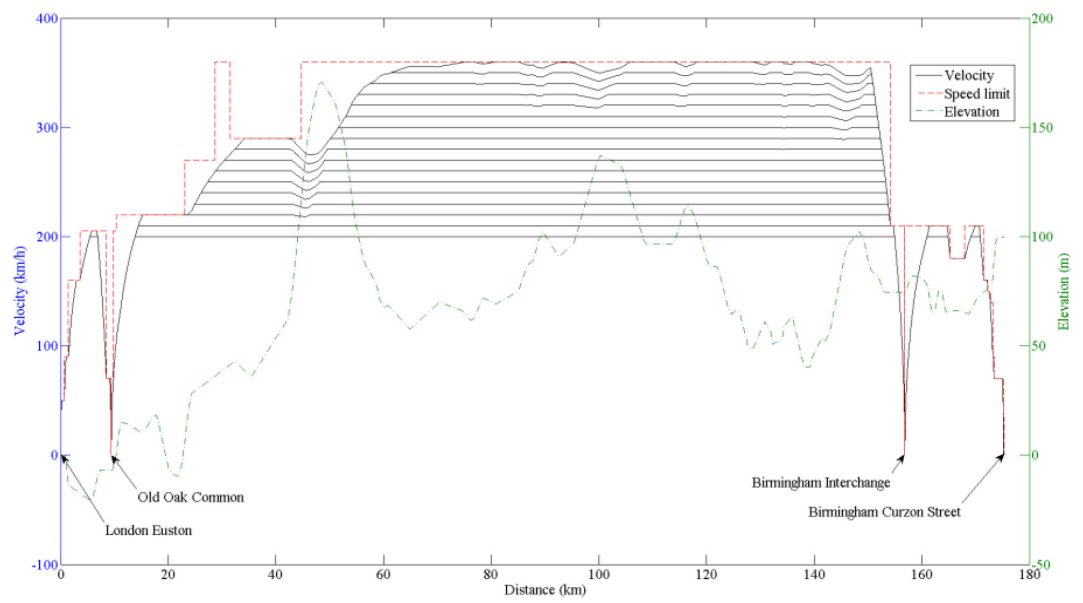

Figure 3: $\quad$ Speed-distance diagram for maximum speeds from $200 \mathrm{~km} / \mathrm{h}$ to $360 \mathrm{~km} / \mathrm{h}$ (step: $10 \mathrm{~km} / \mathrm{h}$ ) and elevation of the route from London to Birmingham.

\subsection{Headway time}

The parameters needed for the headway time calculation are shown in Table 2 . They are available in the reports produced by HS2 [16], where the headway time for plain line with homogenous operation is given with $1600 \mathrm{~m}$ train detection sections. However, the train detection section length has not been finally decided, so headway times for four different detection lengths have been calculated. The calculated headway time on plain line is shown in Figure 4. The headway time at $360 \mathrm{~km} / \mathrm{h}$ with $1600 \mathrm{~m}$ train detection sections is 116 seconds, which is the same as in the report of HS2 [16].

HS2 Ltd calculated the headway time for the line speed of $360 \mathrm{~km} / \mathrm{h}$ even though the normal operating speed is $330 \mathrm{~km} / \mathrm{h}$, because the train can run at the higher speed in the case of delays. The calculation of headway time in our research adopts this concept, in which the headway time is used at a speed up to $30 \mathrm{~km} / \mathrm{h}$ higher than the operational speed is. The headway time increases with speed above an optimal value because the braking distance increases with the square of the speed. Shorter train detection sections give rise to shorter headway times; however, this advantage becomes smaller as speed increases.

Table 2: Parameters for the calculation of headway time for HS2 Phase One.

\begin{tabular}{|l|l|}
\hline Length of train detection section $\left(\mathrm{L}_{\mathrm{d}}\right)$ & $0 \mathrm{~m}, 400 \mathrm{~m}, 800 \mathrm{~m}, 1600 \mathrm{~m}$ \\
\hline Length of train $\left(\mathrm{L}_{\mathrm{t}}\right)$ & $400 \mathrm{~m}$ \\
\hline Length of buffer $\left(\mathrm{L}_{\mathrm{b}}\right)$ & $\begin{array}{l}300 \mathrm{~m}+0.02 *\left(\mathrm{~L}_{\mathrm{d}}+\mathrm{L}_{\mathrm{t}}\right) \mathrm{m} \\
(\text { Odometry tolerance is } 2 \%)\end{array}$ \\
\hline Deceleration rate $(\mathrm{dec})$ & $0.687 \mathrm{~m} / \mathrm{s}^{2}$ \\
\hline Reaction time of the signalling system $(\mathrm{C})$ & $39 \mathrm{~s}$ \\
\hline
\end{tabular}



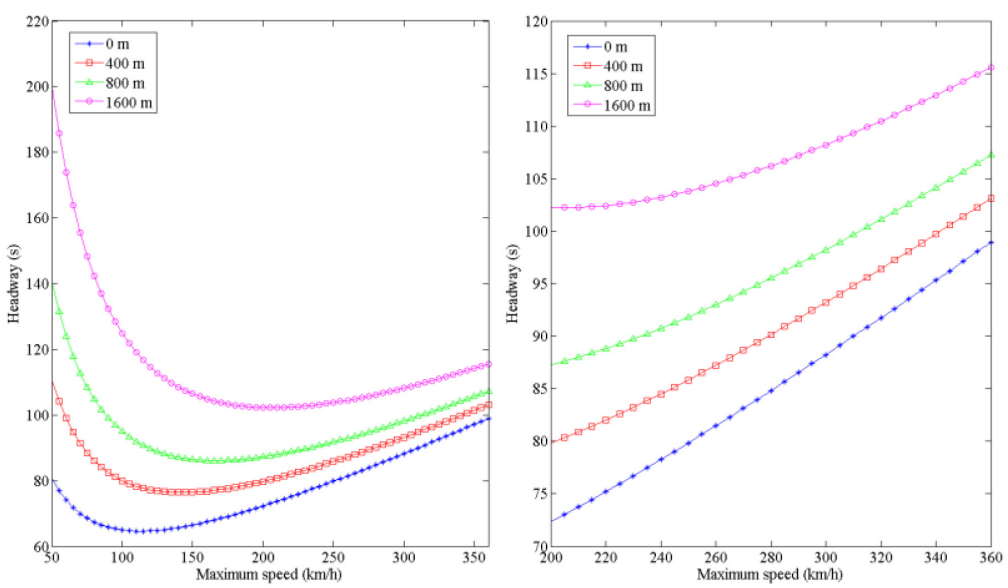

Figure 4: Headway time for plain line for different train detection section lengths.

Figure 4 shows the headway times for train detection section lengths of 0 (equivalent to moving block), 400, 800 and $1600 \mathrm{~m}$ for maximum speeds between $50 \mathrm{~km} / \mathrm{h}$ and $360 \mathrm{~km} / \mathrm{h}$ (left) and between $200 \mathrm{~km} / \mathrm{h}$ and $360 \mathrm{~km} / \mathrm{h}$ (right).

\subsection{Number of trains required}

The proposed service frequency of HS2 Phase One from London Euston to Birmingham Curzon Street is 4 trains per hour at peak times and 3 trains per hour during the off-peak [19]. A cyclic timetable at peak times with 15 minutes between departures was modelled as shown in Figure 5: A train departs from each of the terminal stations at 8:00 and turns around at the other terminal, becoming the opposite direction train that departs at 9:15. At a maximum operational speed of $330 \mathrm{~km} / \mathrm{h}$, the journey time is 49 minutes, requiring that the turnaround time should be less than 26 minutes in order to realise this timetable with 10 train sets. The allowable turnaround times of this timetable with 10 train sets for different journey times is shown in Figure 6. Increase in journey time directly reduces the allowable turnaround time. Several reference minimum planned turnaround times at terminals are also shown in the figure. Tohoku, Joetsu and Nagano Shinkansen turnaround times at Tokyo station are 12 minutes, the Tokaido Shinkansen turnaround time at Tokyo station is 16 minutes and Pendolinos at London Euston station are allowed 25 minutes. If the turnaround time were the same as the lowest amongst the existing HSRs, the model timetable with 10 train sets could be realised with lower maximum speeds of operation. On the other hand, if the turnaround time is fixed at 26 minutes, any decrease in operational speed below $330 \mathrm{~km} / \mathrm{h}$ requires two additional train sets for this timetable to be realised. 


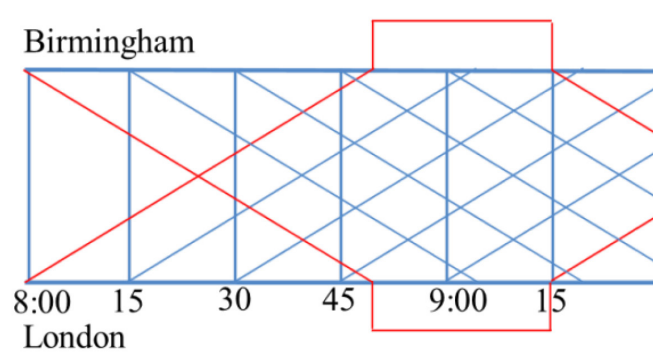

Figure 5: Modelled timetable for the morning peak of HS2 Phase One between London and Birmingham.

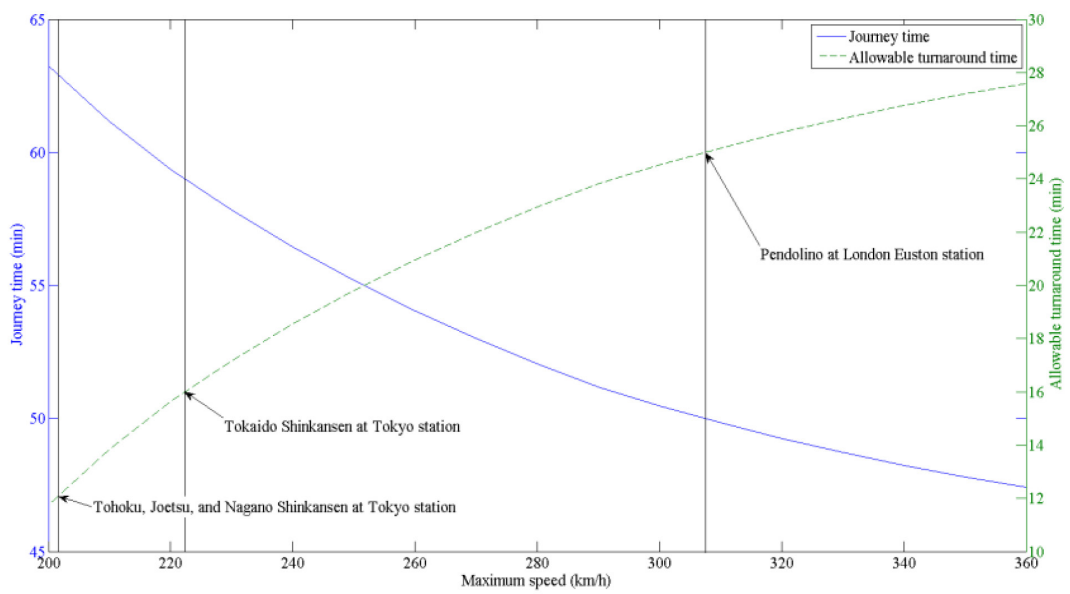

Figure 6: Journey time and allowable turnaround time for the modelled timetable of maximum speeds between $200 \mathrm{~km} / \mathrm{h}$ and $360 \mathrm{~km} / \mathrm{h}$ with 10 train sets.

In Figure 6, the vertical lines indicate reference turnaround times of the Tohoku, Joetsu, and Nagano Shinkansen services at Tokyo station, those of the Tokaido Shinkansen at Tokyo station and the Pendolino services at London Euston station.

\subsection{Analysis of operational options}

Figure 7 shows a summary of the effects of changing the maximum operating speed for HS2 Phase One on the performance indicators of journey time, energy consumption, headway time and allowable turnaround time for 4 trains per hour with 10 train sets. The performance indicators are presented as a percentage of their value when operating at the current planned HS2 maximum speed of operation, that is, $330 \mathrm{~km} / \mathrm{h}$. As mentioned in section 3.2, for the headway time, the minimum headway at $30 \mathrm{~km} / \mathrm{h}$ higher than operational speed, is adopted. 


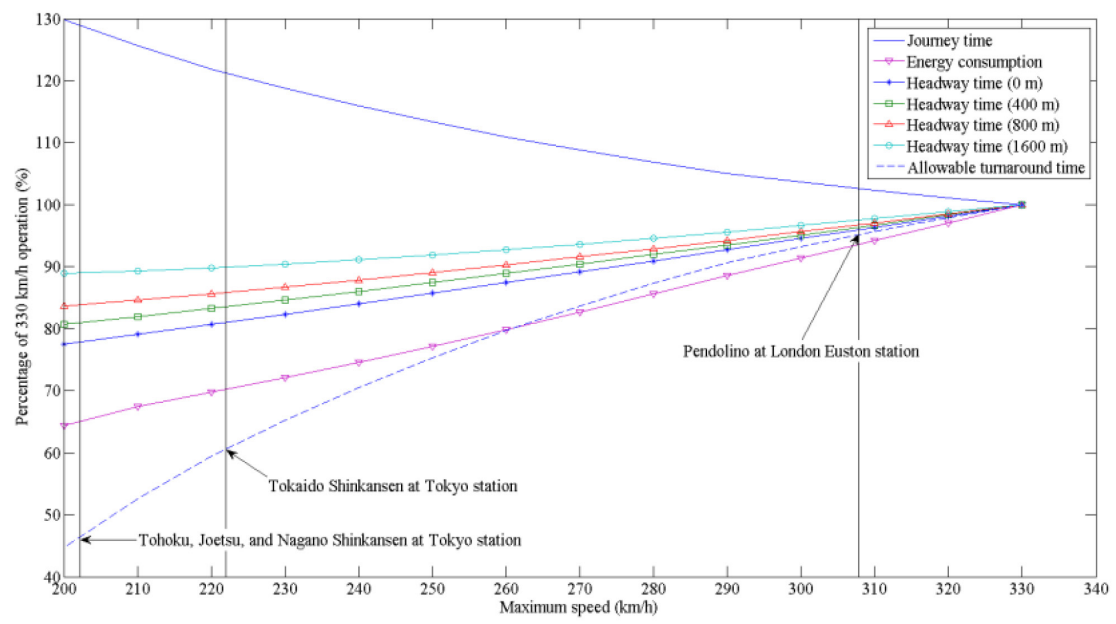

Figure 7: Performance indicators as percentages of values for $330 \mathrm{~km} / \mathrm{h}$ operation.

In Figure 7, the headway times are shown for different lengths of train detection sections $(0,400,800,1600 \mathrm{~m})$. Reference turnaround times at terminals for the Tohoku, Joetsu, and Nagano Shinkansen services, the Tokaido Shinkansen and Pendolino services are shown as vertical lines. From this, some operational options with different maximum speeds can be suggested.

For example, a maximum speed of $310 \mathrm{~km} / \mathrm{h}$ increases journey time by $2.3 \%$, but reduces energy consumption by $5.7 \%$, it reduces headway times by $2-3 \%$ for each train detection section length, and can be realised with the same minimum turnaround time as the Pendolino at London Euston station (25 minutes). A maximum speed of $230 \mathrm{~km} / \mathrm{h}$ increases journey time by $21.8 \%$, however, it reduces energy consumption by $27.9 \%$, headway time by $10-20 \%$ depending on train detection section length and the 4 trains per hour timetable with 10 train sets can be realised with the minimum turnaround time of Japanese Shinkansen trains at Tokyo station. Improving turnaround operations can absorb the effects of decreases of maximum speed, and allows the realisation of lower speed operation with less energy use and headway time without requiring more train sets.

\section{Conclusion}

Options of lower maximum speeds with shorter turnaround time for Phase One of HS2 between London Euston and Birmingham Curzon Street have been analysed from an operational point of view. They have the advantage of saving energy and reducing headway time without increasing the number of trains needed. The effect of an increase in journey time on demand is not considered in this paper; however, the impact may be limited because this corridor does not 
face significant competition with air traffic. Conversely, for the longer distances associated with the full opening of the HS2 route, a decrease in maximum speed could have a more negative effect on both business and operations. For a more detailed analysis, a further evaluation of capacity and energy use with timetables with different journey times and headway times and evaluation of resilience of the timetables by multi train simulation should be investigated.

\section{References}

[1] Department for Transport, "The strategic case for HS2", 2013.

[2] R. Kemp, "The European High Speed Network", in Passenger Transport After 2000 AD, 1993, pp. 63-84.

[3] R. Watson, A. Dufour, and D. T. T. Ngoc, "HS2 Traction Energy Modelling", 2009.

[4] A. Garcia, "High speed, energy consumption and emissions", 2010.

[5] Jernbaneverket, "A Methodology for Environmental AssessmentNorwegian High Speed Railway Project Phase 2", 2011.

[6] SYSTRA, "Factors affecting carbon impacts of HSR", 2011.

[7] X. Feng, "Optimization of target speeds of high-speed railway trains for traction energy saving and transport efficiency improvement", Energy Policy, vol. 39, no. 12, pp. 7658-7665, Dec. 2011.

[8] X. Feng, J. Feng, K. Wu, H. Liu, and Q. Sun, "Evaluating target speeds of passenger trains in China for energy saving in the effect of different formation scales and traction capacities", Int. J. Electr. Power Energy Syst., vol. 42, no. 1, pp. 621-626, Nov. 2012.

[9] D. Woodland, "Optimisation of Automatic Train Protection Systems", 2004.

[10] L. Peeters, "Cyclic railway timetable optimization", 2003.

[11] International Union of Railways, "Evolution of maximum speed on rails", 2009.

[12] S. Hillmansen and C. Roberts, "Energy storage devices in hybrid railway vehicles: a kinematic analysis", Proc. Inst. Mech. Eng. Part F J. Rail Rapid Transit, vol. 221, no. 1, pp. 135-143, Jan. 2007.

[13] W. Davis and General Electric Review, The tractive resistance of electric locomotives and cars. General Electric, 1926.

[14] W. Hay, Railroad engineering. 1982.

[15] O. Brünger and E. Dahlhaus, "Running time estimation", in Timetable \& Traffic, 2008, pp. 58-82.

[16] High Speed Two Limited, "Summary Report on the Capacity and Capability for the High Speed Network", 2011.

[17] B. Hunyadi, "Capacity evaluation for ERTMS ( European Rail Traffic Management System ) Level 2 operation on HS2", 2011.

[18] SYSTRA, "Operational Concept Study Technical Note: HS2 Capacity and Reliability", 2011.

[19] High Speed Two Limited, "HS2 Project Specification”, 2012. 
[20] ARUP, "HS2 Ltd HS2 London to West Midlands Route Corridor Reviews Journey Time Analysis", 2012.

[21] Department for Transport, "HS2 phase one revised line of route maps Publications - Inside Government - GOV.UK". [Online]. Available: https://www.gov.uk/government/publications/hs2-revised-line-of-routemaps. [Accessed: 19-Jul-2013].

[22] International Union of Railways, "World High Speed Rolling Stock", 2013. 